\title{
Proteolytic processing of SDF-1a by matrix metalloproteinase-2 impairs CXCR4 signaling and reduces neural progenitor cell migration
}

\author{
Hui Peng ${ }^{1,2}$, Yumei $\mathbf{W u}^{1,2}$, Zhiyuan Duan ${ }^{1,2,4}$, Pawel Ciborowski ${ }^{2}$, Jialin C. Zheng ${ }^{1,2,3 凶}$ \\ ${ }^{1}$ Laboratory of Neuroimmunology and Regenerative Therapy, University of Nebraska Medical Center, Omaha, NE 68198, USA \\ 2 Departments of Pharmacology and Experimental Neuroscience, University of Nebraska Medical Center, Omaha, NE 68198, \\ USA \\ ${ }^{3}$ Departments of Pathology and Microbiology, University of Nebraska Medical Center, Omaha, NE 68198, USA \\ ${ }^{4}$ Institute of Genetics and Developmental Biology, Chinese Academy of Sciences, Beijing 100101, China \\ $\triangle$ Correspondence: jzheng@unmc.edu \\ Received August 29, 2012 Accepted September 28, 2012
}

\section{ABSTRACT}

Neural stem cells and neural progenitor cells (NPCs) exist throughout life and are mobilized to replace neurons, astrocytes and oligodendrocytes after injury. Stromal cell-derived factor 1 (SDF-1, now named CXCL12) and its receptor CXCR4, an $\alpha$-chemokine receptor, are critical for NPC migration into damaged areas of the brain. Our previous studies demonstrated that immune activated and/or HIV-1-infected human monocyte-derived-macrophages (MDMs) induced a substantial increase of SDF-1 production by human astrocytes. However, matrix metalloproteinase (MMP)-2, a protein up-regulated in HIV-1-infected macrophages, is able to cleave four amino acids from the $\mathrm{N}$-terminus of SDF-1, resulting in a truncated SDF-1(5-67). In this study, we investigate the diverse signaling and function induced by SDF-1 $\alpha$ and SDF-1(5-67) in human cortical NPCs. SDF-1(5-67) was generated by incubating human recombinant SDF-1a with MMP-2 followed by protein determination via mass spectrometry, Western blotting and ELISA. SDF-1a induced time-dependent phosphorylation of extracellular signal-regulated kinases (ERK) 1/2, Akt-1, and diminished cyclic adenosine monophosphate (CAMP). In contrast, SDF-1(5-67) failed to induce these signaling. SDF-1 $\alpha$ activation of CXCR4 induced migration of NPCs, an effect that is dependent on ERK1/2 and Akt-1 pathways; whereas SDF-1(5-67) failed to induce NPC migration. This observation provides evidence that MMP-2 may affect NPC migration through post-translational processing of SDF-1 $\alpha$.

KEYWORDS proteolysis, chemokine, neurogenesis, and migration

\section{INTRODUCTION}

Neural stem cells and neural progenitor cells (NPCs) exist in the adult mammalian central nervous system (CNS). Two important features of NPCs are self-renewal and multipotency, meaning NPCs can give rise to neurons, astrocytes, and oligodendrocytes and therefore replace lost cells in the CNS (Weiss et al., 1996; Alvarez-Buylla et al., 2000; Gage, 2000). NPC migration is an essential process for neurogenesis that occurs in the adult CNS (Hatten, 1999; Gage, 2002). Following injury to the CNS, NPCs preferentially migrate to damaged areas of the brain to facilitate repair, indicating that agents present in the damaged tissue guide the migration of precursor cells (Sun et al., 2004; Belmadani et al., 2006; Chi et al., 2006; Ke et al., 2006; Takeuchi et al., 2007; Wu, 2012). Chemokines, such as stromal cell-derived factor (SDF)-1a, are important mediators of this process (Ceradini et al., 2004; Imitola et al., 2004).

The CXC chemokine SDF-1, known as CXCL12, is a key regulator of B cell lymphopoiesis (Nagasawa et al., 1996; Ma et al., 1998), hematopoietic stem cell mobilization (Aiuti et al., 1997), and leukocyte migration. In addition to the immune system, SDF-1 and its receptor CXCR4 also have important functions in the nervous system. Both SDF-1 and CXCR4 are constitutively expressed at high levels in the developing and 
adult nervous system (Bajetto et al., 1999; Peng et al., 2004; Tran et al., 2004; Peng et al., 2007). SDF-1/CXCR4 signaling regulates the migration and development of neural stem cells that form numerous structures in the brain and peripheral nervous systems (Zou et al., 1998; Bagri et al., 2002; Lu et al., 2002; Reiss et al., 2002; Lazarini et al., 2003; Zhu et al., 2012). Recent data have demonstrated that SDF-1/CXCR4 signaling continues to play a role in the regulation of adult neurogenesis in response to brain injury, and that cells proximal to areas of brain injury upregulate the expression of SDF-1 to attract progenitor cells for repair purposes (Ceradini et al., 2004; Imitola et al., 2004). Previous studies in our lab demonstrated that HIV-1 infected and immunecompetent macrophages, which are the principal target cells and mediators of neuronal injury and death in HIV-1-associated dementia (HAD), induced a substantial increase in SDF-1 production by human astrocytes (Peng et al., 2006). However, matrix metalloproteinase (MMP)-2, which is markedly upregulated in the brain and cerebrospinal fluid of patients with AIDS, could cleave the first four amino acids from the $\mathrm{N}$-terminus of SDF-1, yielding a truncated SDF-1(5-67) (Conant et al., 1999; Johnston et al., 2000; Zhang et al., 2003). Unlike SDF-1a, SDF-1(5-67) failed to bind to its cognate receptor, CXCR4, and caused neurotoxicity and apoptosis. However, whether SDF-1(5-67) affects NPC function, neurogenesis and potential repair processes remains unclear.

In this study, we investigate the diverse signaling and function induced by SDF-1 $\alpha$ and SDF-1(5-67) in human cortical NPCs. We found that MMP-2 cleaves SDF-1a, yielding an N-terminally truncated SDF-1(5-67) that losses its ability to induce CXCR4 signaling and chemotactic function in human NPCs.

\section{RESULTS}

\section{Proteolysis of SDF-1a by MMP-2}

Modification of SDF-1a structure and function was investigated following in vitro exposure of the chemokine to active MMP-2. Human recombinant SDF-1a was incubated with active MMP-2 at different enzyme/substrate ratios. SDF-1a and reaction products was detected by Western blot analysis using either a monoclonal antibody (mAb), recognizing an epitope encoded in the amino-terminal part of the chemokine, or a polyclonal antibody (pAb), recognizing multiple epitopes of SDF-1 1 . We observed that incubation of SDF-1 $\alpha$ with active MMP-2 (1:10 and 1:1, ratio of MMP-2 and SDF-1) led to the loss of the amino-terminal epitope recognized by the $\mathrm{mAb}$ (Fig. 1A). The slight change on the electrophoretic mobility which revealed by pAb blot, proved the discrete modification undergone by the chemokine (Fig. 1B).

Generation of cleavage product over time was measured using Western blot analysis with polyclonal antibody; which detects both cleaved and intact SDF-1a forms (Fig. 1C). MMP-2-mediated cleavage of SDF-1 $\alpha$ occurred with very similar kinetics, as previously described, with half of product being cleaved in 30-60 min (McQuibban et al., 2001).

The amino-terminal cleavage of SDF-1 $\alpha$ was also detected by RP-HPLC combined with ELISA. MMP-2 treated SDF-1 $\alpha$ (1:10 ratio for MMP-2/SDF-1, $w / w)$ and an untreated
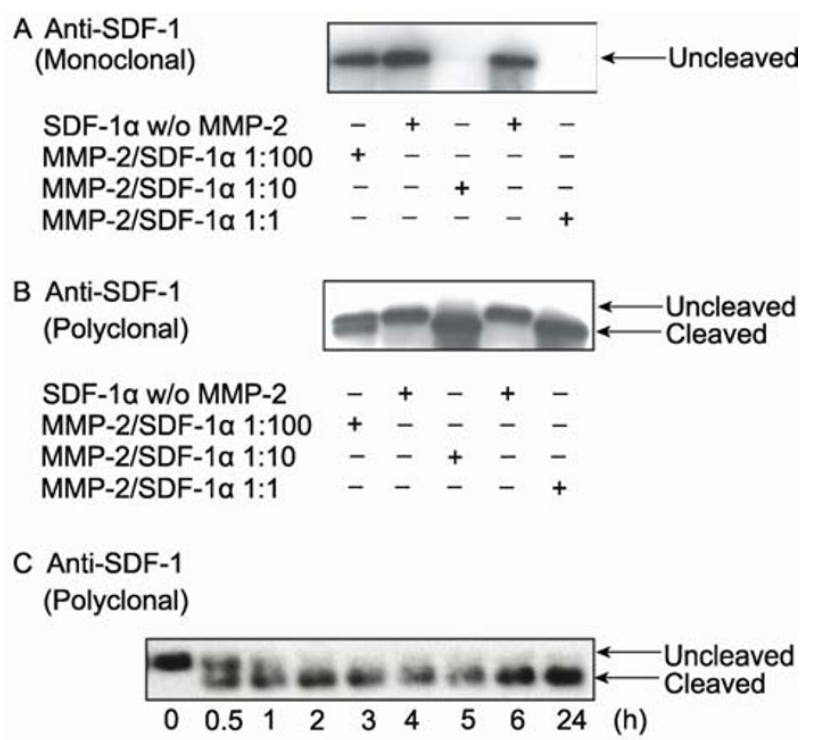

D

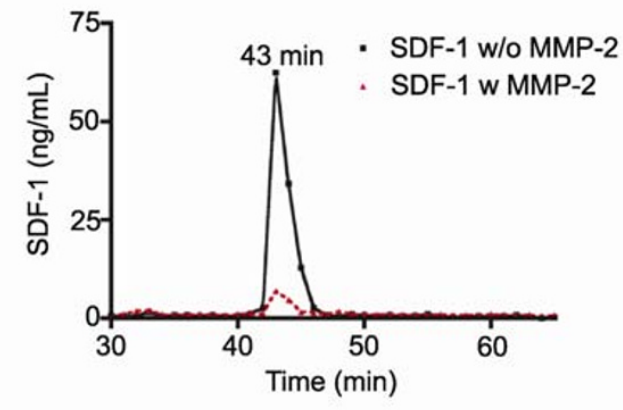

Figure 1. Western blot and RP-HPLC analysis of SDF-1a cleavage by MMP-2. (A and B) SDF-1 $\alpha$ was treated with different concentrations of active MMP-2 (with MMP/SDF-1 $\alpha$ ratios, 1:100, $1: 10$ and $1: 1, w / w, 4 \mathrm{~h}$ treatment at $37^{\circ} \mathrm{C}$ ). SDF-1 $\alpha$ in control and MMP-2 treated samples were detected by Western blot with antibodies for SDF-1 [monoclonal (A) and polyclonal (B)]. Results are representative of three independent experiments. (C) SDF-1 $\alpha$ $(1 \mu \mathrm{g})$ was incubated with MMP-2 $(10 \mathrm{ng})$ at $37^{\circ} \mathrm{C}$, and reaction products were taken at the following time points: $0,30 \mathrm{~min}, 1 \mathrm{~h}$, $2 \mathrm{~h}, 3 \mathrm{~h}, 4 \mathrm{~h}, 5 \mathrm{~h}, 6 \mathrm{~h}$ and $24 \mathrm{~h}$. Reaction products were electrophoresed in $15 \%$ Tris-HCI SDS-PAGE and blotted with antibody for SDF-1 (polyclonal). Results are representative of three independent experiments. (D) SDF-1 (100 ng) and MMP-2-treated SDF-1 (with MMP-2/SDF-1 $\alpha$ of 1:10 and incubated for 4 h) samples were passed through a RP-HPLC column, followed by subsequent detection of SDF-1 by ELISA. SDF-1 $\alpha$ was present in fractions $42-46 \mathrm{~min}$. 
SDF-1 $1 \alpha$ control were separated by RP-HPLC and collected as fractions. The level of SDF-1 in each collected fraction was determined using a monoclonal SDF-1 antibody-based ELI$\mathrm{SA}$. The amino-terminal cleavage of SDF-1 $\alpha$ was evident based on a significantly decreased peak of SDF-1 at $43 \mathrm{~min}$ (retention time) after the MMP-2 treatment (Fig. 1D).

To identify SDF-1 1 residues cleaved by MMP-2, we analyzed SDF-1 $\alpha$ degradation products by electrospray mass spectrometry. For this purpose, SDF-1 $\alpha$ was incubated with MMP-2 for $4 \mathrm{~h}$ at $37^{\circ} \mathrm{C}$ and loaded to the chip pre-treated with anti-SDF-1 polyclonal antibody. A polypeptide of molecular mass $7538 \mathrm{Da}$ was detected as the major molecular species generated upon cleavage and corresponded to an SDF-1a fragment lacking the amino-terminal Lys ${ }^{1}-$ Pro $^{2}-$ Val $^{3}-$ Ser $^{4}$ sequence (Fig. 2). This finding confirms that the amino terminus of SDF-1 $\alpha$ is the proteolytic target by MMP-2.

\section{SDF-1(5-67) failed to induce NPC signaling in human cortical NPCs}

SDF-1 binds to the chemokine receptor CXCR4 and triggers signaling through a pertussis toxin-sensitive, G-protein-dependent, intracellular signaling pathway. We previously reported that SDF-1a binding to CXCR4 mediates trimeric GTP-binding G-inhibitory protein activation and induces inhibition of adenylate cyclase, activates MAP kinase and increases intracellular calcium in human and rat NPCs (Peng et al., 2004). In this study, we examined if MMP-2 cleavage of four amino acids from N-terminus of SDF-1 $\alpha$ will affect SDF-1 $\alpha$ mediated NPC signaling. To generate SDF-1(5-67), we incubated recombinant SDF-1 $\alpha$ with active MMP-2 (1:10 ratio of MMP-2 and SDF-1) for $4 \mathrm{~h}$ as described. As shown in
Fig. 3, SDF-1 $\alpha$ inhibited FSK-stimulated cAMP production in a dose-dependent manner. SDF-1(5-67) showed a decreased effect compared to intact SDF-1 $\alpha$. Next, we examined the effects of SDF-1 $\alpha$ on mitogen-activated protein (MAP) kinase extracellular signal-regulated kinases $1 / 2$ (ERK1/2), and Akt activation. Notably, after cleavage with MMP-2, the fragmented SDF-1 $\alpha$ [SDF-1(5-67)] lost its ability to activate ERK1/2 and Akt (Fig. 4).

\section{Impaired chemotactic activity by SDF-1(5-67)}

SDF-1 binds to its specific cell surface receptor, CXCR4, and is a potent chemoattractant for NPCs. We next examined if MMP-2 cleavage of SDF-1 $\alpha$ will affect the ability of this chemokine to mediate NPC migration. The effect of SDF-1 $\alpha$ and SDF-1(5-67) on NPC migration was tested by their abilities to direct chemotaxis across membranes in NeuroProbe chemotaxis chambers. SDF-1a induced concentration-dependent migration of NPCs. At the concentration that SDF-1 $\alpha$ induced a significant NPC migration, its MMP-2 derived fragment, SDF-1(5-67), was unable to stimulate migration of NPCs (Fig. 5A).

SDF-1 binds and activates the chemokine receptor CXCR4 as well as the more recently identified CXCR7 receptor. However, SDF-1a-induced NPC migration was CXCR4 dependent as confirmed by the total inhibition by T140, a CXCR4 specific antagonist (Fig. 5B). The migration can also be completely blocked by phosphoinositide 3-kinase inhibitors LY294002 and MAP kinase/ERK inhibitor (PD98059), whereas P38 inhibitor (SB203580) had no significant effect on SDF-1 $\alpha$-induced migration (data not shown). This result suggests the demissal of SDF-1(5-67) in NPC

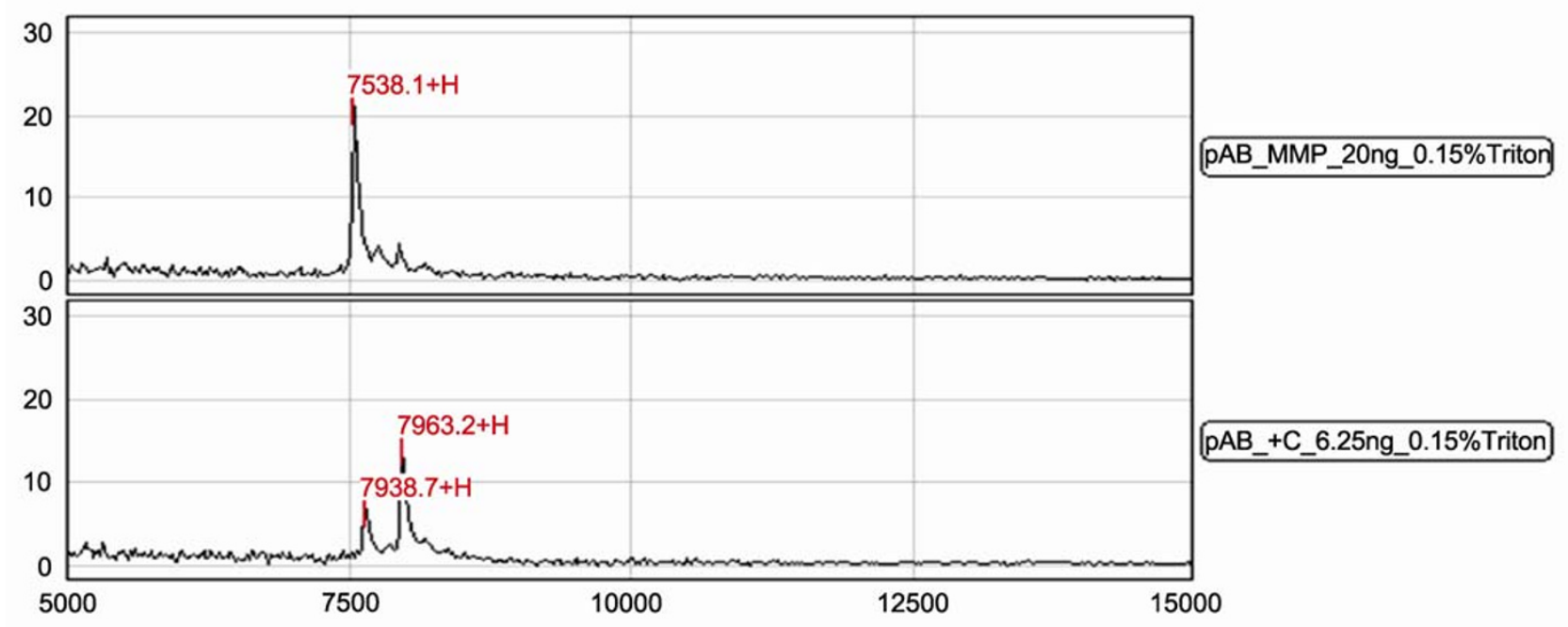

Figure 2. Mass spectrometry analysis of SDF-1 $\alpha$ degradation by MMP-2. PS10 ProteinChip ${ }^{\circledR}$ Array (Preactivated Surface) was treated overnight with $200 \mathrm{ng}$ of SDF-1 polyclonal antibody (R\&D Systems) per spot in a humidity box at $4^{\circ} \mathrm{C}$. Samples were applied to each spot in a sample solution at a final concentration of $0.15 \%$ Triton X-100/PBS. Chips were read on the SELDI (Ciphergen ${ }^{\circledR}$ ) using the Ciphergen ProteinChip ${ }^{\circledR}$ Software program [SDF-1a: KPVSLSYRCPCR......7963 Da; SDF-1(5-67): LSYRCPCR.....7552 Da, minus 17 Da for NH 3 , 7535Da; SDF-1(4-67), SLSYRCPCR......7639 Da]. 


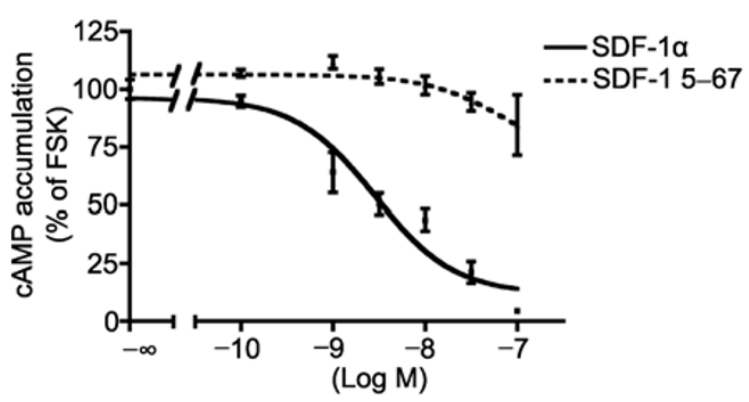

Figure 3. Effect of SDF-1a and SDF-1(5-67) on CAMP accumulation. Human NPCs were cultured at density of $1 \times 10^{5}$ cells/ well in 24-well poly-D-lysine-coated plates for $24 \mathrm{~h}$. Cells were loaded with $5 \mu \mathrm{Ci}\left[{ }^{3} \mathrm{H}\right]$-adenine at $37^{\circ} \mathrm{C}$ for 90-120 min and then treated with $30 \mu \mathrm{mol} / \mathrm{L}$ forskolin with or without different concentrations of SDF-1 $\alpha$ or SDF-1(5-67). Intracellular $\left[{ }^{3} \mathrm{H}\right]$ cAMP was extracted overnight with ice-cold $5 \%$ trichloroacetic acid (TCA) containing $1 \mathrm{mmol} / \mathrm{L}$ unlabeled cAMP (an internal control). [ $\left.{ }^{3} \mathrm{H}\right]$ CAMP was separated from titrated nucleotides by sequential ion-exchange chromatography over Dowex and Alumina columns. The adenosine triphosphate (ATP) and cAMP fractions were collected, and the radioactivity was determined by liquid scintillation spectroscopy. Values were expressed and the percentage conversions of $\left[{ }^{3} \mathrm{H}\right]$ ATP to $\left.{ }^{3} \mathrm{H}\right]$ cAMP. Results are average of three independent experiments.

A

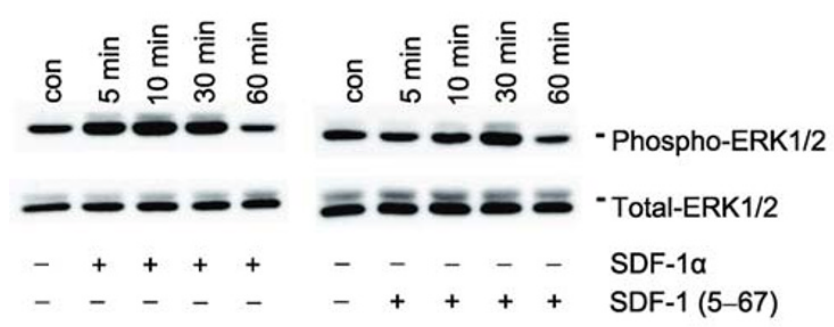

C

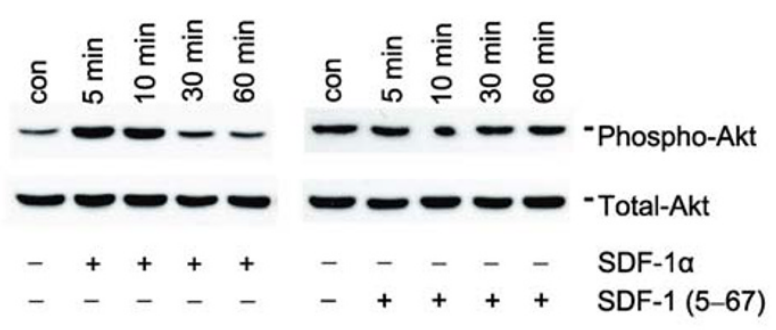

signaling may result in impaired chemotactic activity by SDF-1(5-67).

\section{DISCUSSION}

SDF-1, a constitutively expressed chemokine in the brain, is vital for normal brain development and tissue homeostasis. In addition to transcriptional regulation of expression following cytokine exposure (Peng et al., 2006), SDF-1 expression is also regulated at post-transcriptional levels. It has been suggested that selective proteolysis of SDF-1 is part of the mechanism regulating biological functions in both homeostatic and pathologic processes. The $\mathrm{N}$-terminal domain of SDF-1 was shown to be efficiently processed by a number of proteases, including MMP (McQuibban et al., 2001; Zhang et al., 2003; Vergote et al., 2006), leukocyte elastase (Valenzuela-Fernandez et al., 2002), cathepsin G (Delgado et al., 2001), and dipeptidyl peptidase IV (CD26) (Proost et al., 1998; Shioda et al., 1998; Sadir et al., 2004). Structure-function analysis of SDF-1 has identified that the $\mathrm{N}$-terminal region of SDF-1 (Lys ${ }^{1}-$ Pro $^{2}$ residues) is critical for CXCR4 binding and activation (Crump et al., 1997). Therefore, the discrete proteolysis of the SDF-1 amino terminus by these enzymes generates an inactive chemokine for CXCR4 signaling (McQuibban et al., 2001; Valenzuela-Fernandez et al., 2002; Sadir et al., 2004).

B

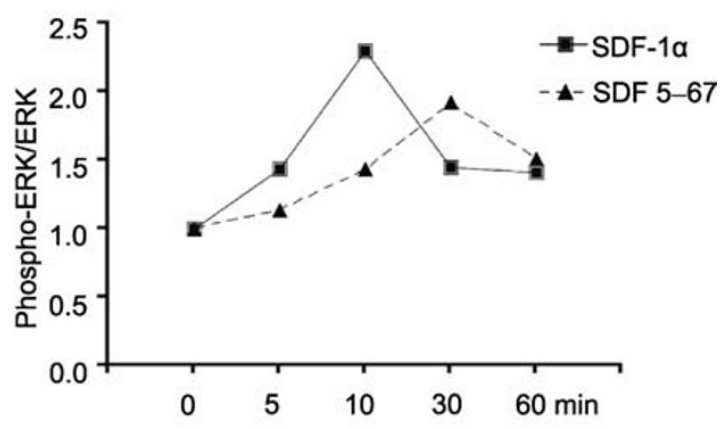

D

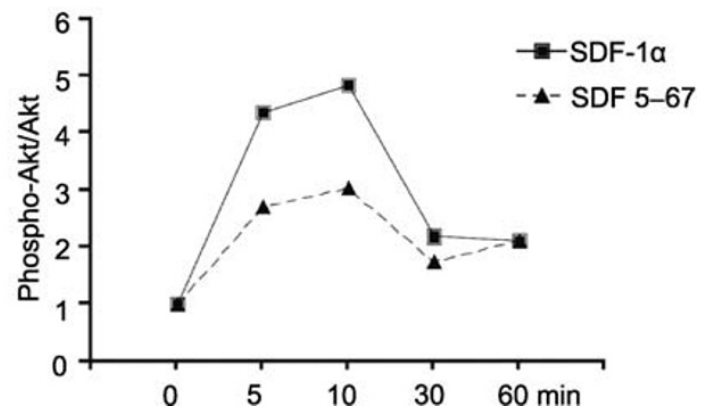

Figure 4. Effects of SDF-1 $\alpha$ and SDF-1(5-67) on ERK1/2 and Akt phosphorylation in human NPCs. Human cortical NPCs were deprived of growth factor medium for $12 \mathrm{~h}$ before being treated with SDF-1a $(10 \mathrm{ng} / \mathrm{mL})$, and SDF-1(5-67) for 5, 10, 30 and $60 \mathrm{~min}$. Western blot analysis with antibody specific for the phosphorylated ERK1/2 (A) or Akt (C) showed increased phosphorylation (activation) of ERK1/2 (A) or Akt (C) while SDF-1(5-67) did not. (B and D) Data was shown as the ratio of phosphorylated and total protein intensity. Results are representative of three independent experiments. 

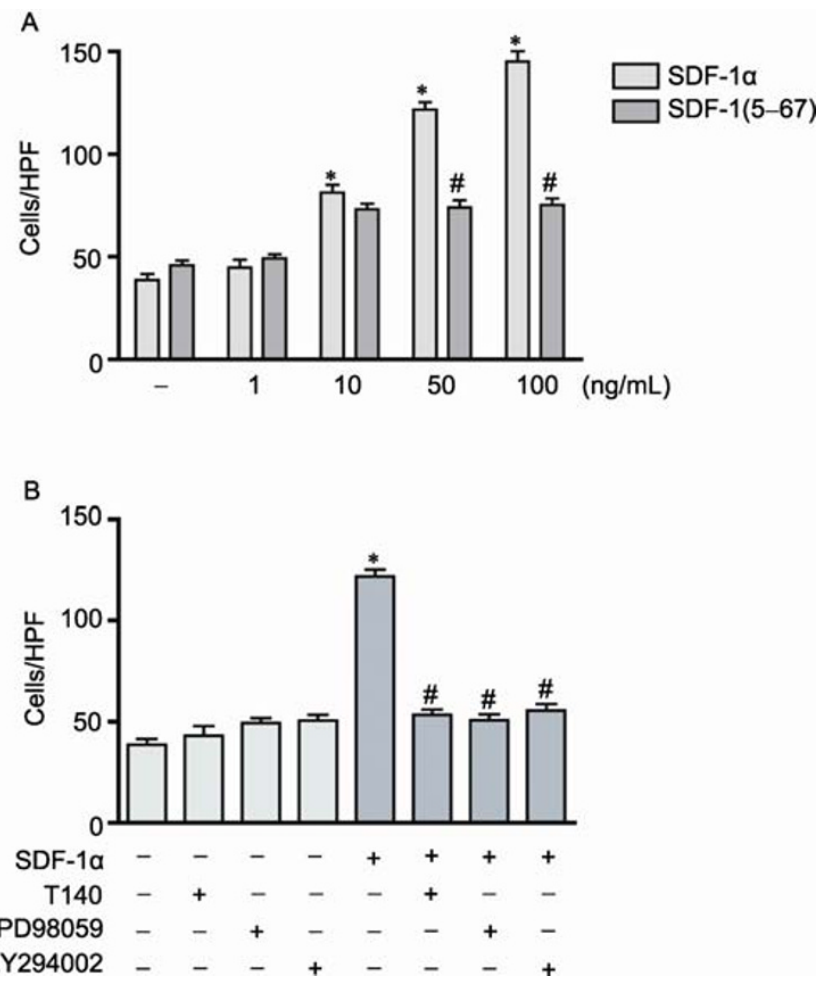

Figure 5. Effect of SDF-1 $\alpha$ and SDF-1(5-67) on human NPC migration. (A) The chemotactic response of human NPCs was determined by counting migrating cells per high-powered field (HPF, 400x) \pm SEM in each quadruplicate well using NeuroProbe chemotaxis chambers. Human NPCs migrated in a dose-dependent manner toward SDF-1 $\alpha$. SDF-1(5-67) showed reduced cell migration compared to SDF-1a. (B) NPC chemotactic response to $50 \mathrm{ng} / \mathrm{mL}$ SDF-1a was completely abolished in cells pretreated with the CXCR4 antagonist T140 (30 nmol/L), phosphoinositide 3-kinase inhibitor LY294002, and MAP kinase/ERK inhibitor (PD98059). Data represent two separate experiments that were carried out in quadruplicate. ${ }^{*} P<0.05$ in comparison to control. \# $P<$ 0.05 in comparison to SDF- $1 \alpha$.

In this current study, we further confirmed that MMP-2 cleaved SDF-1 $\alpha$ at Ser-Leu ${ }^{5}$ and generated a SDF-1 $\alpha$ fragment, SDF-1(5-67) (Figs. 1 and 2). SDF-1(5-67) failed to induce intracellular signaling through MAP kinase activation and cAMP accumulation (Figs. 3 and 4 ) in human NPCs. The failure to induce phosphorylation of ERK1/2 and Akt, which are critical for SDF-1a induced-NPC migration, resulted in failure of NPC migration induced upon SDF-1(5-67) treatment (Fig. 5). MMP-2 efficiently converts SDF-1a from a potent chemoattractant to a molecule, SDF-1(5-67), devoid of its chemoattractant activity. These data suggest that MMP-2 may modulate the neurogenesis process through cleavage and inactivation of SDF-1.

Previous studies demonstrated SDF-1(5-67) lost binding to its cognate receptor CXCR4, but induced neurotoxicity through an inducible $\mathrm{G}$ protein-coupled receptor CXCR3 (McQuibban et al., 2001; Vergote et al., 2006; Zhang et al., 2003). However, human NPCs express very low level of CXCR3 as detected by real-time RT-PCR (less than $1 \%$ as compared to CXCR4 expression in NPCs and less than $11 \%$ as compared to NPC differentiated neurons, data not shown). Therefore, in our study, we did not observe a significant effect of SDF-1(5-67) on NPC viability (data not shown). This may be due to the resistance of NPCs to cell death signaling (Peng et al., 2005) and low expression of CXCR3 in human NPCs as compared to mature neurons (Vergote et al., 2006).

During neurodegenerative disorders (for example HAD, multiple sclerosis, Parkinson's and Alzheimer's diseases), alterations in neurogenesis contribute to disease pathogenesis. Patients with HAD possess fewer adult neural progenitor cells in the dentate gyrus of the hippocampus, an important center for memory and learning, than noninfected subjects or HIV-infected patients without dementia (Krathwohl and Kaiser, 2004). Our previous studies also demonstrated that HIV-1-infected and/or immune-activated brain macrophages affect neurogenesis through inhibition of neurogenesis and activation of gliogenesis (Peng et al., 2008). Here we identify another important route for HIV-infected macrophages influencing neurogenesis through MMP-2 cleavage of SDF-1. Although SDF-1 has been shown to be upregulated in the brain of patients with HIV encephalitis (Langford et al., 2002; Rostasy et al., 2003) and that HIV-1 infected and activated macrophages increased expression of SDF-1 by astrocytes through IL-1 $\beta$, MMP-2 is also markedly upregulated in macrophages after HIV-1 infection (Conant et al., 1999; Johnston et al., 2000). MMP-2 efficiently converts SDF-1a to SDF-1(5-67). Removal of the four amino acids from the $\mathrm{N}$-terminal of SDF-1 $\alpha$ results in failure to induce NPC migration, which may abrogate inflammation-driven NPC migration and further repair. This observation provides evidence that HIV-1-infected and/or immune activated macrophages may affect NPC migration through post-translational regulation of SDF-1 $\alpha$.

\section{MATERIALS AND METHODS}

\section{Western blot analysis of SDF-1a proteolysis}

SDF-1a $(1 \mu \mathrm{g})$ was incubated with MMP-2 (EMD Chemicals, Gibbstown, NJ) using different enzyme/substrate ratios of 1:1, 1:10 and $1: 100(w / w)$ and different times at $37^{\circ} \mathrm{C}$ in CAB $(150 \mathrm{mmol} / \mathrm{L}$ $\mathrm{NaCl}, 20 \mathrm{mmol} / \mathrm{L}$ Tris, $5 \mathrm{mmol} / \mathrm{L} \mathrm{CaCl}, \mathrm{pH} 7.5$ ), as previously described (McQuibban et al., 2001). Reaction products were electrophoresed in $15 \%$ Tris SDS-PAGE gels, transferred to an Immuno-Blot polyvinylidene fluoride (PVDF) membrane (Bio-Rad, Hercules, CA), and probed with both a polyclonal anti-SDF antibody (1:1000 dilution) to bind multiple epitopes of SDF-1 $\alpha$ and a monoclonal anti-SDF-1 antibody (1:1000 dilution) to detect the amino-terminal part of the chemokine. Membranes were blotted with 
with horseradish peroxidase (HRP)-conjugated secondary antibodies (1:10,000; Cell Signaling Technologies) and then developed using Enhanced Chemiluminescent (ECL) solution (Pierce).

\section{RP-HPLC followed by ELISA analysis of SDF-1a proteolysis}

SDF-1a $(1 \mu \mathrm{g})$ was incubated with MMP-2 (1:10 ratio for MMP-2/SDF-1, $w / w)$ for $4 \mathrm{~h}$ and the reaction products along with untreated SDF-1 $\alpha$ were separated by RP-HPLC and collected as fractions. Different fractions were collected following HPLC and the levels of SDF-1 $\alpha$ were determined using a monoclonal SDF-1 antibody based ELISA, as previously described (Peng et al., 2006).

\section{Mass spectrometry analysis of SDF-1 $\alpha$ proteolysis}

Covalent bonding of anti-SDF-1 antibody to the surface of PS10 ProteinChip ${ }^{\circledR}$ Array (Preactivated Surface) was performed following the manufacturer's recommendations. Briefly, the chip was treated overnight with 200 ng of anti-SDF-1 polyclonal antibody (R\&D Systems) per spot in a humidity box at $4^{\circ} \mathrm{C}$. The spots were then blocked twice for $30 \mathrm{~min}$ at room temperature (RT) using fresh-made 0.5 $\mathrm{mol} / \mathrm{L}$ Tris- $\mathrm{HCl} \mathrm{pH}$ 8.0. Blocked spots were washed twice using $0.25 \%$ Triton X-100 in PBS. Samples were applied to each spot in a sample solution at a final concentration of $0.15 \%$ Triton X-100/PBS and incubated for $60 \mathrm{~min}$ at RT in a humidity box. Sample spots were washed twice with $0.25 \%$ Triton $\mathrm{X}-100$ for $5 \mathrm{~min}$ and then briefly rinsed with HPLC grade water and allowed to dry for $5 \mathrm{~min}$ before application of $1 \mu \mathrm{L}$ of $50 \%$ SPA (sinapic acid solution, $30 \% \mathrm{ACN}$, $15 \%$ isopropanol, $0.5 \%$ TFA) matrix to each spot. The matrix was allowed to dry and an additional $1 \mu \mathrm{L}$ of $50 \%$ SPA was again applied to each spot and allowed to dry. Spectra were collected using PBS II ProteinChip Biosystems (Ciphergen Biosystems, city and state) mass analyzer. Analysis was performed using the Ciphergen ProteinChip ${ }^{\circledR}$ Software.

\section{Human neural progenitor cell culture}

Human cortical NPCs were isolated from human fetal brain tissue as previously described (Peng et al., 2004). Briefly, NPCs were cultured in substrate-free tissue culture flasks and grown as spheres in neurosphere initiation medium (NPIM), which consisted of X-Vivo 15 (BioWhittaker, Walkersville, ME) with N2 supplement (Gibco BRL, Carlsbad, CA), neural cell survival factor-1 (NSF-1, BioWhittaker), basic fibroblast growth factor (bFGF, $20 \mathrm{ng} / \mathrm{mL}$, Sigma-Aldrich, St. Louis, MO), epidermal growth factor (EGF, $20 \mathrm{ng} / \mathrm{mL}$, Sigma-Aldrich), leukemia inhibitory factor (LIF, $10 \mathrm{ng} / \mathrm{mL}$, Chemicon, Temecula, CA), and $60 \mathrm{ng} / \mathrm{mL} \mathrm{N}$-acetylcysteine (Sigma-Aldrich). Cells were passaged at two-week intervals, as previously described (Peng et al., 2004).

\section{Cyclic adenosine monophosphate (cAMP) assay}

The assay for cAMP accumulation was performed, as previously described, with modifications (Zheng et al., 1999; Peng et al., 2004). Briefly, NPCs were loaded with $5 \mu \mathrm{Ci}\left[{ }^{3} \mathrm{H}\right]$-adenine (NEN Life Science
Product, Boston, MA) at $37^{\circ} \mathrm{C}$ for $90-120 \mathrm{~min}$ and treated with 30 $\mu \mathrm{mol} / \mathrm{L}$ forskolin (Sigma-Aldrich) with or without different concentrations of SDF-1 $\alpha$ or SDF-1(5-67). Intracellular [ ${ }^{3} \mathrm{H}$ ] cAMP was extracted overnight with ice-cold $5 \%$ trichloroacetic acid (TCA) containing $1 \mathrm{mmol} / \mathrm{L}$ unlabeled cAMP (an internal control). [ ${ }^{3} \mathrm{H}$ ]cAMP was separated from titrated nucleotides by sequential ion-exchange chromatography over Dowex and Alumina columns (Sigma-Aldrich). The adenosine triphosphate (ATP) and cAMP fractions were collected, and the radioactivity was determined by liquid scintillation spectroscopy. Values were expressed as the percentage conversions of $\left[{ }^{3} \mathrm{H}\right] \mathrm{ATP}$ to $\left[{ }^{3} \mathrm{H}\right] \mathrm{cAMP}$.

\section{Western blot for NPC signaling}

NPCs were lysed with M-PER Protein Extraction Buffer (Pierce, Rockford, IL) containing 1xprotease inhibitor cocktail (Roche Diagnostics, Indianapolis, IN). Protein concentration was determined using the BCA Protein Assay Kit (Pierce). Proteins (10-20 $\mu \mathrm{g}$ ) were separated by $10 \%$ SDS-polyacrylamide gel electrophoresis (PAGE) and then transferred to a PVDF membrane. After blocking in PBS/Tween $(0.01 \%)$ with $5 \%$ nonfat milk, the membrane was incubated with primary antibodies overnight at $4^{\circ} \mathrm{C}$ followed by horseradish peroxidase-conjugated secondary antibodies (1:10,000; Cell Signaling Technologies) and then developed using Enhanced Chemiluminescent (ECL) solution (Pierce). For data quantification the films were scanned with a CanonScan 9950F scanner and the acquired images were then analyzed on a Macintosh computer using the public domain $\mathrm{NIH}$ image program (developed at the U.S. National Institutes of Health and available on the internet at http://rsb.info.nih.gov/nih- image/).

\section{Chemotaxis assay}

The in vitro migration of human NPCs in response to SDF-1 $\alpha$ and SDF-1(5-67) was carried out using polyvinylcarbonate-free membranes with $8 \mu \mathrm{m}$ pore size in 96-well microchemotaxis chambers (NeuroProbe, Cabin John, MD), as previously described, with modifications (Klein et al., 2001; Peng et al., 2004). Briefly, $300 \mu \mathrm{L}$ of Ex Vivo 15 containing $0.1 \%$ BSA with or without SDF-1a or SDF-1(5-67) was placed into the lower compartment. A $50-\mu \mathrm{L}$ aliquot of dissociated NPC suspension $\left(5 \times 10^{5}\right.$ cells $\left./ \mathrm{mL}\right)$ was added in the upper compartment of each well. For inhibition studies, cells were pretreated with $100 \mathrm{ng} / \mathrm{mL}$ of pertussis toxin (PTX) and inhibitors for $1 \mathrm{~h}$. Plates were incubated at $37^{\circ} \mathrm{C}$ for $4 \mathrm{~h}$, and migrated NPCs were counted in the lower chamber in four microscopic fields per quadruplicate well at 400X magnification. Results were expressed as mean number of cells migrating per microscopic field \pm standard error of the mean (SEM).

\section{Statistical analyses}

Data were expressed as means \pm SD or SEM. The data were evaluated statistically by analysis of variance (ANOVA) followed by the Tukey test for paired observations. Significance was considered to be $P<0.05$. To account for any donor-specific differences, all experiments were performed with NPCs from at least three donors. All assays were performed a minimum of two times, with triplicate or 
quadruplicate samples in each.

\section{ACKNOWLEDGEMENTS}

We kindly acknowledge Dr. Yunlong Huang and Mrs. Kristin Leland Wavrin who provided valuable comments and suggestion about the manuscript. This work was supported by research grants by the National Institutes of Health: R21 NS066841 to HP; R01 NS41858, R01 NS61642m P20 RR15635 and P01 NS 43985 to JZ.

\section{ABBREVIATIONS}

cAMP, cyclic adenosine monophosphate; CNS, central nervous system; ECL, Enhanced Chemiluminescent; ERK, extracellular signal-regulated kinase; HAD, HIV-1-associated dementia; HRP, horseradish peroxidase; mAb, monoclonal antibody; MAP, mitogen-activated protein; MDM, monocyte-derived-macrophage; MMP-2, matrix metalloproteinase 2; NPC, neural progenitor cell; pAb, polyclonal antibody; PVDF, polyvinylidene fluoride; SDF, stromal cell-derived factor

\section{REFERENCES}

Aiuti, A., Webb, I.J., Bleul, C., Springer, T., and Gutierrez-Ramos, J.C. (1997). The chemokine SDF-1 is a chemoattractant for human CD34+ hematopoietic progenitor cells and provides a new mechanism to explain the mobilization of CD34+ progenitors to peripheral blood. J Exp Med 185, 111-120.

Alvarez-Buylla, A., Herrera, D.G., and Wichterle, H. (2000). The subventricular zone: source of neuronal precursors for brain repair. Prog Brain Res 127, 1-11.

Bagri, A., Gurney, T., He, X., Zou, Y.R., Littman, D.R., Tessier-Lavigne, M., and Pleasure, S.J. (2002). The chemokine SDF1 regulates migration of dentate granule cells. Development 129, 4249-4260.

Bajetto, A., Bonavia, R., Barbero, S., Florio, T., Costa, A., and Schettini, G. (1999). Expression of chemokine receptors in the rat brain. Ann N Y Acad Sci 876, 201-209.

Belmadani, A., Tran, P.B., Ren, D., and Miller, R.J. (2006). Chemokines regulate the migration of neural progenitors to sites of neuroinflammation. J Neurosci 26, 3182-3191.

Ceradini, D.J., Kulkarni, A.R., Callaghan, M.J., Tepper, O.M., Bastidas, N., Kleinman, M.E., Capla, J.M., Galiano, R.D., Levine, J.P., and Gurtner, G.C. (2004). Progenitor cell trafficking is regulated by hypoxic gradients through HIF-1 induction of SDF-1. Nat Med 10, 858-864.

Chi, L., Ke, Y., Luo, C., Li, B., Gozal, D., Kalyanaraman, B., and Liu, R. (2006). Motor neuron degeneration promotes neural progenitor cell proliferation, migration, and neurogenesis in the spinal cords of amyotrophic lateral sclerosis mice. Stem Cells 24, 34-43.

Conant, K., McArthur, J.C., Griffin, D.E., Sjulson, L., Wahl, L.M., and Irani, D.N. (1999). Cerebrospinal fluid levels of MMP-2, 7, and 9 are elevated in association with human immunodeficiency virus dementia. Ann Neurol 46, 391-398.

Crump, M.P., Gong, J.H., Loetscher, P., Rajarathnam, K., Amara, A.,
Arenzana-Seisdedos, F., Virelizier, J.L., Baggiolini, M., Sykes, B.D., and Clark-Lewis, I. (1997). Solution structure and basis for functional activity of stromal cell-derived factor-1; dissociation of CXCR4 activation from binding and inhibition of HIV-1. EMBO J 16, 6996-7007.

Delgado, M.B., Clark-Lewis, I., Loetscher, P., Langen, H., Thelen, M., Baggiolini, M., and Wolf, M. (2001). Rapid inactivation of stromal cell-derived factor-1 by cathepsin $\mathrm{G}$ associated with lymphocytes. Eur J Immunol 31, 699-707.

Gage, F.H. (2000). Mammalian neural stem cells. Science 287, 1433-1438.

Gage, F.H. (2002). Neurogenesis in the adult brain. J Neurosci 22, 612-613.

Hatten, M.E. (1999). Central nervous system neuronal migration. Annu Rev Neurosci 22, 511-539.

Imitola, J., Raddassi, K., Park, K.I., Mueller, F.J., Nieto, M., Teng, Y.D., Frenkel, D., Li, J., Sidman, R.L., Walsh, C.A., et al. (2004). Directed migration of neural stem cells to sites of CNS injury by the stromal cell-derived factor 1alpha/CXC chemokine receptor 4 pathway. Proc Natl Acad Sci U S A 101, 18117-18122.

Johnston, J.B., Jiang, Y., van Marle, G., Mayne, M.B., Ni, W., Holden, J., McArthur, J.C., and Power, C. (2000). Lentivirus infection in the brain induces matrix metalloproteinase expression: role of envelope diversity. J Virol 74, 7211-7220.

Ke, Y., Chi, L., Xu, R., Luo, C., Gozal, D., and Liu, R. (2006). Early response of endogenous adult neural progenitor cells to acute spinal cord injury in mice. Stem Cells 24, 1011-1019.

Klein, R.S., Rubin, J.B., Gibson, H.D., DeHaan, E.N., Alvarez-Hernandez, X., Segal, R.A., and Luster, A.D. (2001). SDF-1 alpha induces chemotaxis and enhances Sonic hedgehog-induced proliferation of cerebellar granule cells. Development 128, 1971-1981.

Krathwohl, M.D., and Kaiser, J.L. (2004). HIV-1 promotes quiescence in human neural progenitor cells. J Infect Dis 190, 216-226.

Langford, D., Sanders, V.J., Mallory, M., Kaul, M., and Masliah, E. (2002). Expression of stromal cell-derived factor 1alpha protein in HIV encephalitis. J Neuroimmunol 127, 115-126.

Lazarini, F., Tham, T.N., Casanova, P., Arenzana-Seisdedos, F., and Dubois-Dalcq, M. (2003). Role of the alpha-chemokine stromal cell-derived factor (SDF-1) in the developing and mature central nervous system. Glia 42, 139-148.

Lu, M., Grove, E.A., and Miller, R.J. (2002). Abnormal development of the hippocampal dentate gyrus in mice lacking the CXCR4 chemokine receptor. Proc Natl Acad Sci U S A 99, 7090-7095.

Ma, Q., Jones, D., Borghesani, P.R., Segal, R.A., Nagasawa, T., Kishimoto, T., Bronson, R.T., and Springer, T.A. (1998). Impaired B-lymphopoiesis, myelopoiesis, and derailed cerebellar neuron migration in CXCR4 and SDF 1 deficient mice. Proc Natl Acad Sci U S A 95, 9448-9453.

McQuibban, G.A., Butler, G.S., Gong, J.H., Bendall, L., Power, C., Clark-Lewis, I., and Overall, C.M. (2001). Matrix metalloproteinase activity inactivates the CXC chemokine stromal cell-derived factor-1. J Biol Chem 276, 43503-43508.

Nagasawa, T., Hirota, S., Tachibana, K., Takakura, N., Nishikawa, S., Kitamura, Y., Yoshida, N., Kikutani, H., and Kishimoto, T. (1996). Defects of B-cell lymphopoiesis and bone-marrow myelopoiesis in mice lacking the CXC chemokine PBSF/SDF-1. Nature 382, 
635-638.

Peng, H., Erdmann, N., Whitney, N., Dou, H., Gorantla, S., Gendelman, H.E., Ghorpade, A., and Zheng, J. (2006). HIV-1-infected and/or immune activated macrophages regulate astrocyte SDF-1 production through IL-1beta. Glia 54, 619-629.

Peng, H., Huang, Y., Duan, Z., Erdmann, N., Xu, D., Herek, S., and Zheng, J. (2005). Cellular IAP1 regulates TRAIL-induced apoptosis in human fetal cortical neural progenitor cells. J Neurosci Res 82, 295-305.

Peng, H., Huang, Y., Rose, J., Erichsen, D., Herek, S., Fujii, N., Tamamura, H., and Zheng, J. (2004). Stromal cell-derived factor 1 mediated CXCR4 signaling in rat and human cortical neural progenitor cells. Journal of Neuroscience Research 76 , 35-50.

Peng, H., Kolb, R., Kennedy, J.E., and Zheng, J. (2007). Differential expression of CXCL12 and CXCR4 during human fetal neural progenitor cell differentiation. J Neuroimmune Pharmacol 2, 251-258.

Peng, H., Whitney, N., Wu, Y., Tian, C., Dou, H., Zhou, Y., and Zheng, J. (2008). HIV-1-infected and/or immune-activated macrophagesecreted TNF-alpha affects human fetal cortical neural progenitor cell proliferation and differentiation. Glia 56, 903-916.

Proost, P., Struyf, S., Schols, D., Durinx, C., Wuyts, A., Lenaerts, J.P., De Clercq, E., De Meester, I., and Van Damme, J. (1998). Processing by CD26/dipeptidyl-peptidase IV reduces the chemotactic and anti-HIV-1 activity of stromal-cell-derived factor-1alpha. FEBS Lett 432, 73-76.

Reiss, K., Mentlein, R., Sievers, J., and Hartmann, D. (2002). Stromal cell-derived factor 1 is secreted by meningeal cells and acts as chemotactic factor on neuronal stem cells of the cerebellar external granular layer. Neuroscience 115, 295-305.

Rostasy, K., Egles, C., Chauhan, A., Kneissl, M., Bahrani, P., Yiannoutsos, C., Hunter, D.D., Nath, A., Hedreen, J.C., and Navia, B.A. (2003). SDF-1alpha is expressed in astrocytes and neurons in the AIDS dementia complex: an in vivo and in vitro study. $J$ Neuropathol Exp Neurol 62, 617-626.

Sadir, R., Imberty, A., Baleux, F., and Lortat-Jacob, H. (2004). Heparan sulfate/heparin oligosaccharides protect stromal cell-derived factor-1 (SDF-1)/CXCL12 against proteolysis induced by CD26/dipeptidyl peptidase IV. J Biol Chem 279, 43854-43860.

Shioda, T., Kato, H., Ohnishi, Y., Tashiro, K., Ikegawa, M., Nakayama, E.E., Hu, H., Kato, A., Sakai, Y., Liu, H., et al. (1998). Anti-HIV-1 and chemotactic activities of human stromal cell-derived factor 1alpha (SDF-1alpha) and SDF-1beta are abolished by CD26/dipeptidyl peptidase IV-mediated cleavage. Proc Natl Acad Sci U S A 95, 6331-6336.

Sun, L., Lee, J., and Fine, H.A. (2004). Neuronally expressed stem cell factor induces neural stem cell migration to areas of brain injury. J Clin Invest 113, 1364-1374.

Takeuchi, H., Natsume, A., Wakabayashi, T., Aoshima, C., Shimato, S., Ito, M., Ishii, J., Maeda, Y., Hara, M., Kim, S.U., et al. (2007). Intravenously transplanted human neural stem cells migrate to the injured spinal cord in adult mice in an SDF-1- and HGF-dependent manner. Neurosci Lett 426, 69-74.

Tran, P.B., Ren, D., Veldhouse, T.J., and Miller, R.J. (2004). Chemokine receptors are expressed widely by embryonic and adult neural progenitor cells. J Neurosci Res 76, 20-34.

Valenzuela-Fernandez, A., Planchenault, T., Baleux, F., Staropoli, I., Le-Barillec, K., Leduc, D., Delaunay, T., Lazarini, F., Virelizier, J.L., Chignard, M., et al. (2002). Leukocyte Elastase Negatively Regulates Stromal Cell-derived Factor-1 (SDF-1)/CXCR4 Binding and Functions by Amino-terminal Processing of SDF- 1 and CXCR4. J Biol Chem 277, 15677-15689.

Vergote, D., Butler, G.S., Ooms, M., Cox, J.H., Silva, C., Hollenberg, M.D., Jhamandas, J.H., Overall, C.M., and Power, C. (2006). Proteolytic processing of SDF-1alpha reveals a change in receptor specificity mediating HIV-associated neurodegeneration. Proc Natl Acad Sci U S A 103, 19182-19187.

Weiss, S., Reynolds, B.A., Vescovi, A.L., Morshead, C., Craig, C.G., and van der Kooy, D. (1996). Is there a neural stem cell in the mammalian forebrain? Trends Neurosci 19, 387-393.

Wu, Y., Chen, Q., Peng, H., Dou, H., Zhou, Y., Huang, Y., and Zheng, J. (2012). Directed migration of human nueral progenitor cells to interleukin- $1 \beta$ is promoted by chemokines stromal cell-derived factor-1 and monocyte chemotactic factor-1 in mouse brains. Translational Neurodegeneration 31, 15.

Zhang, K., McQuibban, G.A., Silva, C., Butler, G.S., Johnston, J.B., Holden, J., Clark-Lewis, I., Overall, C.M., and Power, C. (2003). HIV-induced metalloproteinase processing of the chemokine stromal cell derived factor- 1 causes neurodegeneration. Nat Neurosci 6, 1064-1071.

Zheng, J., Thylin, M., Ghorpade, A., Xiong, H., Persidsky, Y., Cotter, R., Niemann, D., Che, M., Zeng, Y., Gelbard, H., et al. (1999). Intracellular CXCR4 signaling, neuronal apoptosis and neuropathogenic mechanisms of HIV-1-associated dementia. J Neuroimmunol 98, 185-200.

Zhu, B., Xu, D., Deng, X., Chen, Q., Huang, Y., Peng, H., Li, Y., Jia, B., Thoreson, W.B., Ding, W., et al. (2012). CXCL12 Enhances Human Neural Progenitor Cell Survival through a CXCR7- and CXCR4- mediated Endocytotic Signaling Pathway. Stem Cells. (In Press).

Zou, Y.R., Kottmann, A.H., Kuroda, M., Taniuchi, I., and Littman, D.R. (1998). Function of the chemokine receptor CXCR4 in haematopoiesis and in cerebellar development. Nature 393, 595-599. 